\title{
Effect of mitral valvular regurgitation on transthoracic impedance cardiogram ${ }^{\star}$
}

\author{
R M SCHIEKEN, M R PATEL, H L FALSETTI, R M LAUER \\ From the Departments of Pediatrics and Internal Medicine, University of Iowa, Iowa City, Iowa, USA
}

SUMMARY Mitral valvular regurgitation consistently modified the wave form of the first derivative of the transthoracic impedance cardiogram. The transthoracic impedance cardiogram was recorded in 23 control subjects (group 1), and 23 patients with isolated mitral regurgitation (group 2). Simultaneous transthoracic impedance cardiogram, electrocardiogram, and mitral valve echocardiograms in group 1 showed that the primary diastolic wave ("O") of the transthoracic impedance cardiogram occurred synchronously with the maximal opening of the mitral valve. In group 2, the primary systolic wave ( $\mathrm{dZ} / \mathrm{dt}$ max) was diminished, and the " $\mathrm{O}$ " of the transthoracic impedance cardiogram was raised. The area under the systolic wave of the transthoracic impedance cardiogram (S) and the area under the diastolic opening of the transthoracic impedance cardiogram (D) were measured and the ratio $\mathrm{D} /(\mathrm{D}+\mathrm{S})$ calculated. This ratio, called the mitral regurgitation fraction was $(0.50 \pm 0.14)$ in group 2 which was higher than that found in group 1 control subjects $(0 \cdot 11 \pm 0 \cdot 08)$. The mitral regurgitation fraction $(15$ to $77 \%)$ determined by the impedance method was closely correlated with the mitral regurgitation fraction (20 to $74 \%$ ) obtained during cardiac catheterisation; it also increased during isometric handgrip and decreased during amyl nitrite inhalation. In three mitral regurgitation patients the transthoracic impedance cardiogram returned to normal configuration after surgical implantation of a prosthetic mitral valve. These data suggest that the transthoracic impedance cardiogram is quantitatively altered in patients with mitral regurgitation.

The first derivative transthoracic impedance cardiogram is a reproducible wave form with recognisable components. ${ }^{1}$ Fig. 1 shows the relation between these components of the impedance cardiogram and the electrocardiographic and phonocardiographic events as described by Lababidi et al. ${ }^{2}$ These authors emphasised the synchronous relation between the "O" point of the impedance cardiogram and both the phonocardiograph opening snap and the "O" point of the apex cardiogram in patients with mitral stenosis. Quantitative measurements of portions of the impedance cardiogram relate to cardiac output in normal subjects, but are unreliable in patients with either left-to-right shunts or valvular insufficiency. ${ }^{3}$ Preliminary data from our laboratory suggested that the height of the " $O$ " point was increased in patients with mitral regurgitation. ${ }^{4}$ This paper describes the impedance cardiogram wave form changes occurring in patients with mitral valvular regurgitation and explores the

* Supported in part by a grant from the American Heart Association. Received for publication 27 November 1979 degree to which these changes relate to the severity of disease.

\section{Methods}

The impedance cardiogram was recorded in 23 control subjects (group 1) ranging in age from 15 to 55 years (mean 25 years). Twelve of these subjects underwent cardiac catheterisation for the evaluation of atypical chest pain and had normal findings, including selective coronary angiography. The other 11 subjects who did not undergo cardiac catheterisation were normal volunteers with no clinical evidence of cardiac disease as evidenced by normal history, physical examination, electrocardiogram, and echocardiogram.

The study group was formed by 23 consecutive patients with isolated mitral valvular regurgitation (group 2) ranging in age from 18 to 65 years (mean 30 years). The severity of the mitral regurgitation was assessed by cardiac catheterisation as described below. The transthoracic impedance cardiogram 
was recorded in subjects from both groups. Four aluminium electrodes with adhesive backing were placed circumferentially around the neck and abdomen in a standard position. ${ }^{1}$ The outer two electrodes were connected to a constant current source providing a constant sinusoidal current at $100 \mathrm{KHz}$. The inner two electrodes were connected to a high impedance amplifier and suitable circuits (Minnesota impedance cardiogram, model 202) to record the change in electrical impedance during the cardiac cycle. After a $1 \mathrm{ohm} \mathrm{s}{ }^{-1}$ calibration signal, the first derivative of the change in impedance was recorded (Electronics for Medicine recorder, model DR-16) simultaneously with the electrocardiogram at a paper speed of $100 \mathrm{~mm} / \mathrm{s}$. All of the impedance cardiogram recordings were performed in held expiration with avoidance of the Valsalva manoeuvre to minimise respiratory variations. The impedance cardiograms were recorded after the determination of forward cardiac output and before the left ventricular angiogram in patients undergoing cardiac catheterisation.

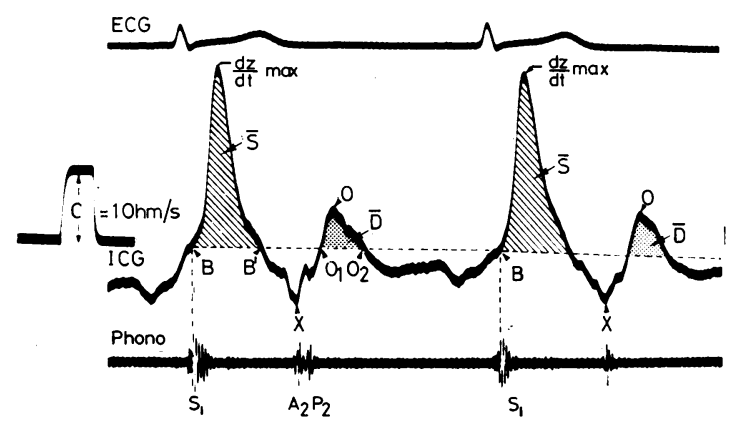

Fig. 1 The impedance cardiogram, electrocardiogram, and phonocardiogram tracings in a control subject showing the measurements for determining the areas $S$ and $D$. The " $C$ " is the calibration signal equal to $1 \mathrm{ohm} / \mathrm{s}$ for the impedance cardiogram. The B point of the impedance cardiogram occurs synchronously with the first heart sound, and the $B$ point marks the beginning of the isovolumetric contraction of the left ventricle. The $X$ point occurs synchronously with the maximal deflection of the aortic sound (A2). The " $O$ " point has been shown to occur synchronously with maximal mitral valve opening. A line is drawn joining the $B$ points of two successive heart beats. This line crosses the impedance cardiogram at three points during one cardiac cycle, $\mathrm{B}, \mathrm{O}_{1}$, and $\mathrm{O}_{2}$. The portion of the impedance cardiogram under $d Z / d t$ max and above the line $B B^{1}$ defines an area during systolic ejection $(S)$. The portion of the impedance cardiogram under the " $O$ " point and above the same line defines an area during early diastole (D). The RR interval is the interval between the two successive $Q R S$ complexes measured in milliseconds (ms).

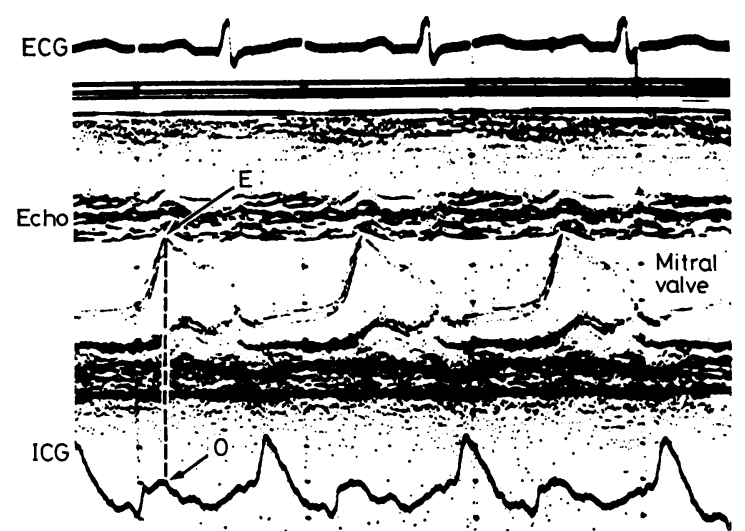

Fig. 2 Simultaneous recordings of the electrocardiogram (ECG), echocardiographic mitral valve tracing (Echo), and the impedance cardiogram (ICG). The echocardiographic maximal mitral valve opening ( $E$ point) occurs synchronously with the ICG " $O$ " point $(O)$.

Fig. 1 illustrates the impedance cardiogram recording in a control subject without mitral regurgitation. The phonocardiogram and electrocardiogram were recorded as reference markers to define the wave form points and areas studied. Phonocardiograms were recorded from the second right intercostal space in all subjects with a frequency filter set from 50 to $100 \mathrm{~Hz}$. The mitral impedance regurgitant fraction (RFI) was calculated as a ratio of the areas $\mathrm{D} / \mathrm{D}+\mathrm{S}$.

Simultaneous echocardiograms of the mitral valve, impedance cardiograms, and electrocardiograms were recorded in 11 control subjects (Fig. 2). The echocardiogram was recorded using a Smith Kline Ekoline-20 Ultrasonoscope with $2 \cdot 25$ or $3 \cdot 5$ $\mathrm{mHz}$ transducer with a $1 \mu \mathrm{s}$ transmission time and a repetition rate of $1000 / \mathrm{s}$. The intervals from the $Q$ wave of the electrocardiogram to the " $O$ " point of the impedance cardiogram and the $Q$ wave to the echocardiograph maximal opening of the mitral valves ( $E$ point) were measured.

The effects of isometric exercise and amyl nitrite inhalation upon the impedance cardiogram were evaluated in five normal subjects from group 1 and 12 subjects with mitral regurgitation from group 2. The impedance cardiogram was recorded during the second minute of sustained isometric handgrip ( $25 \%$ of the predetermined individual maximum). After a five minute rest period the impedance cardiogram was recorded in these subjects during inhalation of amyl nitrite.

Three patients with mitral regurgitation had both preoperative and postoperative impedance 
cardiograms. Fig. 3 illustrates both the preoperative impedance cardiogram and the changes that occurred after the placement of a prosthetic mitral valve.

The severity of the mitral valvular regurgitation was assessed in group 2 subjects during cardiac catheterisation. Cardiac output was determined by the Fick method and the stroke volume calculated. Expired air was collected for three minutes in a Douglas bag and the percentage of oxygen measured using a Beckman oxygen analyser. The arteriovenous oxygen differences were measured using an Instrumentation Laboratory Co-oximeter. Left ventricular single plane cineangiograms in the right anterior oblique projection were performed during held deep inspiration within 15 minutes after the Fick cardiac output measurements. ${ }^{5}$ The cineangiographic left ventricular volumes (end-diastolic and end-systolic) were determined by the area-length method. ${ }^{6}$ The estimates of the true left ventricular volumes were obtained by correcting these angiographic volumes by using the unified regression formulae. ${ }^{8}$ For calculated end-diastolic volume greater than $110 \mathrm{ml} / \mathrm{m}^{2}$ body surface area and/or ejection fraction less than 40 per cent, the unified formula was used. Mitral regurgitant fraction was calculated by dividing the difference between the angiographic left ventricular stroke volume and forward fixed stroke volume by the angiographic left ventricular stroke volume. ${ }^{9-11}$

One way analysis of variance was used to examine the significance of group difference. The paired $t$ test was used to determine the significance of changes during isometric exercise and amyl nitrite inhalation. Linear regression analysis was used to evaluate the correlation between the two methods. The estimates of reliability were obtained using an intraclass correlation coefficient. ${ }^{12}$

\section{Results}

The impedance cardiogram measurements in

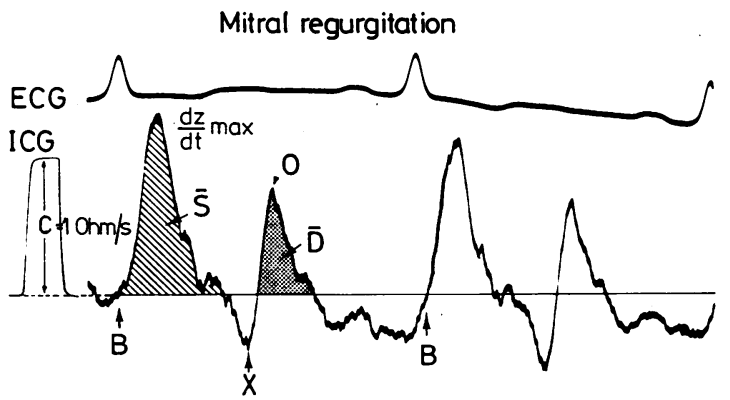

Post mitral prosthesis
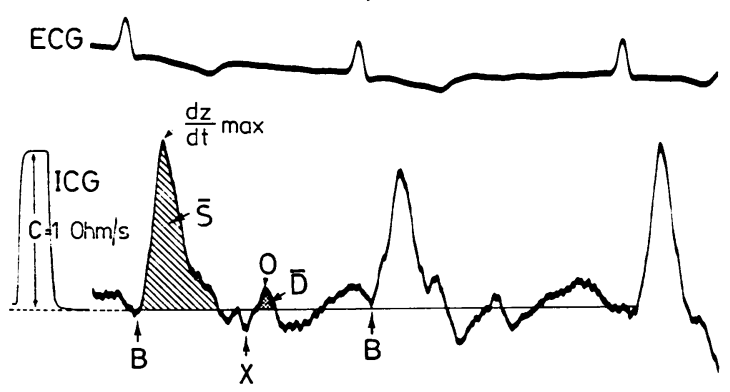

Fig. 3 ICG recordings in mitral regurgitation and post-mitral prosthesis in the same patient. The " $O$ " point is raised and $D$ is a larger proportion of $S$ with mitral regurgitation. The " $O$ " point returned to normal and $D$ became a smaller proportion of $S$ with prosthetic valve placement.

normal subjects and patients with mitral regurgitation are described in Table 1 . There were significant differences between the normal subjects and those with mitral regurgitation. The height of the " $O$ " point (ohms s${ }^{-1}$ ) and the area under $\mathrm{dZ} / \mathrm{dt} / \mathrm{max}(\mathrm{S})$ were different. The calculated mitral RFI (the ratio $\mathrm{D} / \mathrm{D}+\mathrm{S})$ in group $2(0 \cdot 50 \pm 0 \cdot 14)$ was greater than control $(0 \cdot 11 \pm 0 \cdot 08)$. The $R R$ intervals in both were similar. Thus, these data demonstrate consistent

Table 1 Mean $\perp S D$ of first derivative impedance cardiogram measurements in control subjects and mitral regurgitation patients

\begin{tabular}{|c|c|c|c|c|c|c|c|}
\hline Subjects & $\begin{array}{l}d z / d t \max \\
\left(o h m s s^{-1}\right)\end{array}$ & $\begin{array}{l}\text { "X" } \\
(\text { ohms s }\end{array}$ & $\begin{array}{l}\text { "O" } \\
(\text { ohms s-1) }\end{array}$ & $\begin{array}{l}\bar{S} \\
\text { (ohms) }\end{array}$ & $\begin{array}{l}\bar{D} \\
\text { (ohms) }\end{array}$ & $\begin{array}{l}\text { Mitral } R F_{\mathbf{I}} \\
\bar{D} i(\bar{D}+\bar{S})\end{array}$ & $\begin{array}{l}\text { RR interval } \\
\text { (ms) }\end{array}$ \\
\hline $\begin{array}{l}\text { Group } 1 \\
\text { Control subjects }(n=23) \\
\text { Group } 2 \\
\text { Mitral regurgitation subjects }(n-23)\end{array}$ & $\begin{array}{l}2.66 \pm 0.73 \\
1.38+1.12 \star\end{array}$ & $\begin{array}{l}0.85 \pm 0.37 \\
0.55+0.50\end{array}$ & $\begin{array}{l}0.45 \div 0.28 \\
0.98+0.43 \star\end{array}$ & $\begin{array}{l}2.94+1.06 \\
1.09+0.76^{\star}\end{array}$ & $\begin{array}{l}0.44 \pm 0.39 \\
1.03 \pm 0.50 \star\end{array}$ & $\begin{array}{l}0.11 \pm 0.08 \\
0.50+0.14 \star\end{array}$ & $\begin{array}{l}894 \pm 239 \\
799+217\end{array}$ \\
\hline
\end{tabular}

* Significance level less than 0.05 from group 1 (control subjects).

The statistical significance levels were determined by one way analysis of variance.

$\overline{\mathrm{S}}$ and $\overline{\mathrm{D}}$ are areas under $\mathrm{dz}$ 'dt $\max$ and " $\mathrm{O}$ " as defined. 
changes in the impedance cardiogram wave form in patients with mitral regurgitation.

Fig. 4 shows the relation between the mitral $R_{\text {I }}$ and the catheterisation regurgitant fraction. In the 12 control subjects who underwent cardiac catheterisation, the average forward stroke volume $(\mathrm{SVF})$ by Fick method was $65 \mathrm{ml}$ while the average angiographic left ventricular stroke volume (SVA) was $59 \mathrm{ml}$. These stroke volumes were closely related $\left(S S_{A}=0.91 \times S V F-1.79, r=0.90\right)$, indicating that these two methods correlate highly in our laboratory. Fig. 5A shows the quantitative effects of isometric handgrip exercise on the areas $S$ and $D$ and the mitral $R_{I}$ in 12 patients with mitral regurgitation. The area $S$ did not change, but the area $\mathrm{D}$ increased significantly from 0.75 to 1.22 ohms. The mitral $R F_{1}$ increased significantly from 0.47 to 0.57 . The $R R$ interval decreased from 920 to 700 milliseconds $(p<0.01)$ which is consistent with an increase in heart rate in response to isometric exercise. In contrast, the control subjects (Table 2) not show any significant impedance cardiogram changes.

Fig. 5B shows the effects of amyl nitrite inhalation in five of these 12 patients with mitral rgurgitation. The area $S$ increased significantly from 0.90 to $1.54 \mathrm{ohms}$ while the area D showed no significant

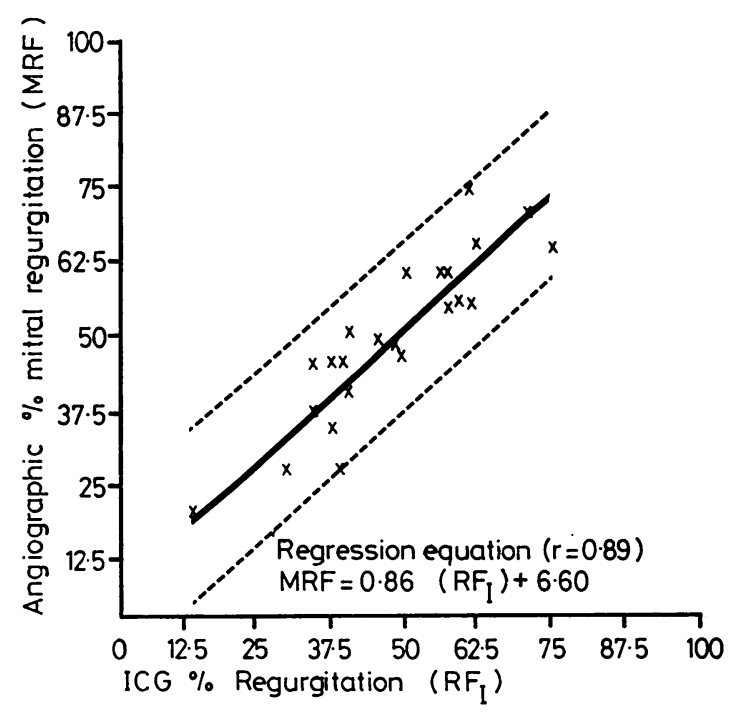

Fig. 4 Correlation between percent regurgitation estimated from the impedance cardiogram, mitral $R F_{I}$, and mitral regurgitant percentage calculated from angiographic left ventricular stroke volume and forward stroke volume. The centre heavy line is a regression line and dotted lines indicate the 95 per cent confidence region for new observations.
Table 2 Quantitative effects of isometric handgrip exercise and amyl nitrite inhalation in five control subjects

\begin{tabular}{|c|c|c|c|c|}
\hline Condition & $\begin{array}{l}S \\
\text { (ohms) }\end{array}$ & $\begin{array}{l}D \\
\text { (ohms) }\end{array}$ & Mitral $R F_{\mathbf{I}}$ & $\begin{array}{l}R R \text { interval } \\
\text { (ms) }\end{array}$ \\
\hline $\begin{array}{l}\text { Resting } \\
\text { Handgrip } \\
\text { Amyl nitrite }\end{array}$ & $\begin{array}{l}2.27 \pm 0.41 \\
1.97 \pm 0.38 \\
1.90 \pm 0.76\end{array}$ & $\begin{array}{l}0.43 \pm 0.20 \\
0.28 \pm 0.33 \\
0.43 \pm 0.30\end{array}$ & $\begin{array}{l}0.15 \pm 0.04 \\
0.11 \pm 0.10 \\
0.17 \pm 0.08\end{array}$ & $\begin{array}{r}1060 \pm 100 \\
904 \pm 59^{\star} \\
648 \pm 110^{\star}\end{array}$ \\
\hline
\end{tabular}

^Indicates significance level at 5 per cent level from resting condition. The RR interval decreased significantly with these alterations in afterload but the mitral RFI did not show any significant change. These indicate that the mitral RFI does not change when there is no change in mitral regurgitation, which is true in these control subjects

change. The mitral $\mathrm{RF}_{\mathrm{I}}$ decreased significantly from 0.53 to 0.33 . The RR interval decreased from 800 to 500 milliseconds $(p<0.01)$. The mitral $R F_{I}$ in control subjects (Table 2) showed no significant change with amyl nitrite.

The presence of mitral regurgitation interfered with the ability of the impedance cardiogram to predict the stroke volume. The area $S$, when compared with the forward stroke volume and angiographic stroke volume in all 23 patients with mitral regurgitation, was found to have a linear regression correlation of $r=0.40$ and $r=0.48$, respectively. Furthermore, the area $\mathrm{D}$ was found to have a linear regression correlation of $r=0.50$ when compared with the cardiac catheterisation determined mitral regurgitant volume.

The intraclass correlation coefficient $\left(R_{\mathrm{I}}\right)$ estimates the correlation between repeated measurements made on the same subjects from different sets of recordings. The observed intraclass correlation coefficients of the impedance cardiogram measurements from beat to beat and between the average of three beats obtained from two different sets of recordings were all greater than 0.85 . These data indicate a high degree of reproducibility.

Fig. 3 illustrates the impedance cardiogram tracings in a patient with mitral regurgitation both before and after placement of a prosthetic mitral valve. There is a distinct decrease in the " $O$ " point toward normal after mitral valve replacement. This decrease in the height of the " $O$ " point was noted in all three patients (Table 3 ).

\section{Discussion}

The physical principles which govern changes in the impedance cardiogram are not completely understood. Kubicek and others using simultaneous recordings of the impedance cardiogram and aortic flow measurements in the dog demonstrated that the peak $\mathrm{dZ} / \mathrm{dt} \max$ is correlated to the peak aortic ejection rate. ${ }^{13}$ We have described an impedance cardiogram wave form abnormality which is in- 
fluenced by aortic regurgitation and have shown that this abnormality is related to the clinical severity of the lesion. ${ }^{14}$ The consistent changes in the impedance cardiogram with mitral regurgitation described herein show that the impedance cardiogram reflects changes caused by mitral regurgitation.

The expression $(D+S)$ was used to incorporate both the regurgitant volume $\mathrm{D}$ and stroke volume $S$ as the left ventricular stroke output. Thus the ratio $D / D+S$ resembles the usual regurgitant fraction formula: regurgitant volume divided by left ventricular stroke volume. Multiple factors, including chest size and configuration, might be expected to affect the absolute values of the impedance cardiogram measurements. These factors, however, would be expected to affect both the systolic and
Fig. 5 Bar graphs demonstrating change in the impedance cardiogram indices (mean $+S D$ ) $S, D$, and mitral $R F_{I}$ caused by isometric handgrip in 12 mitral regurgitation patients and by amyl nitrite inhalation in five mitral regurgitation patients. The $S$ and $D$ are in ohms and mitral $R F_{I}$ is in per cent. Note that the scale for mitral $R F_{I}$ begins at 30 per cent instead of 0 per cent. $N S=$ not significant.
A
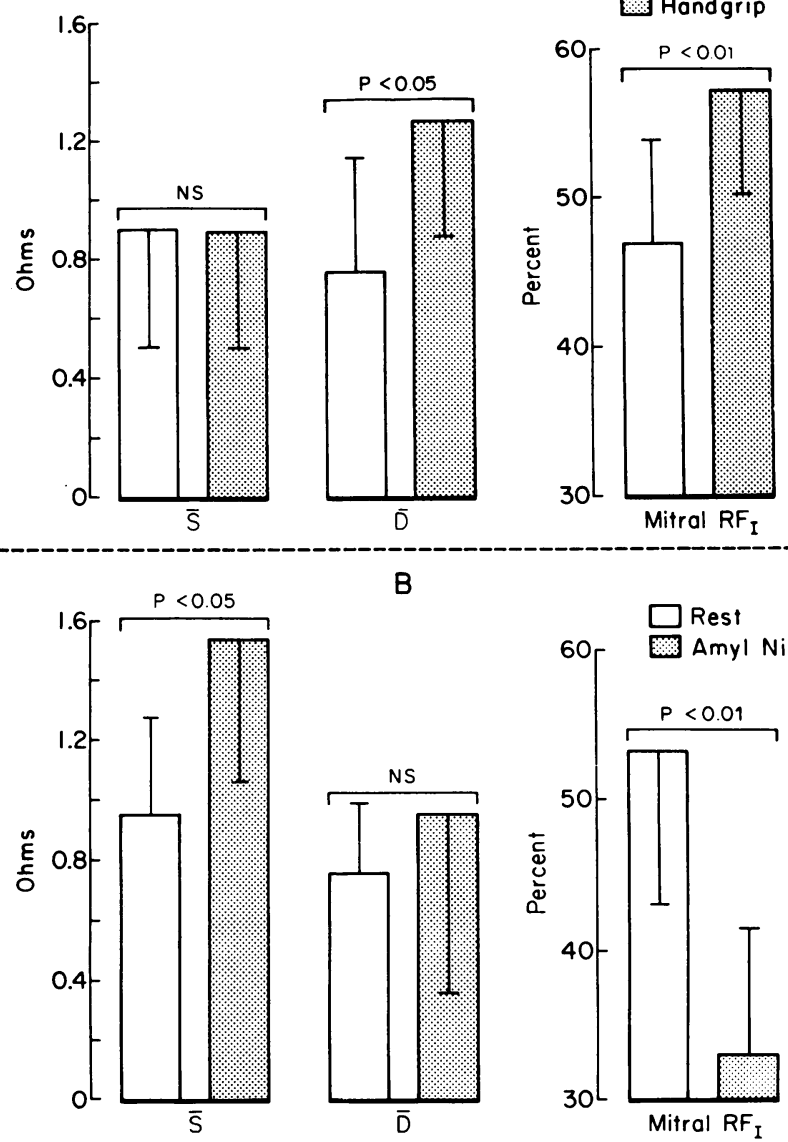

Table 3 Summary of impedance cardiogram indices in three patients with mitral regurgitation before and after mitral valve replacement

\begin{tabular}{|c|c|c|c|c|c|c|}
\hline Condition & $\begin{array}{l}d z / d t \max \\
\left(o h m s s^{-1}\right)\end{array}$ & $\begin{array}{l}S \\
\text { (ohms) }\end{array}$ & $\begin{array}{l}\text { “O”" } \\
\text { (ohms s s) }\end{array}$ & $\begin{array}{l}D \\
\text { (ohms) }\end{array}$ & Mitral $R F_{\mathbf{I}}$ & $\begin{array}{l}R R \text { interval } \\
(\mathrm{ms})\end{array}$ \\
\hline $\begin{array}{l}\text { Presurgical }(n=3) \\
\text { After mitral valve replacement }(n=3)\end{array}$ & $\begin{array}{l}1 \cdot 3 \pm 0 \cdot 14 \\
2 \cdot 4 \pm 0 \cdot 50^{\star}\end{array}$ & $\begin{array}{l}1 \cdot 1 \pm 0 \cdot 3 \\
2 \cdot 2 \pm 0 \cdot 1^{\star}\end{array}$ & $\begin{array}{l}0.9 \pm 0.35 \\
0.2 \pm 0.1^{\star}\end{array}$ & $\begin{array}{l}1 \cdot 05 \pm 0.4 \\
0.15 \pm 0.12 \star\end{array}$ & $\begin{array}{l}0.6 \pm 0.10 \\
0.08 \pm 0.07 \star\end{array}$ & $\begin{array}{l}870 \pm 200 \\
850 \pm 180\end{array}$ \\
\hline
\end{tabular}

*Significantly different at $p<0.05$ from presurgical values.

No significant change in RR interval in both conditions. These values are from the same patients before and after mitral valve replacement. 
diastolic portions of the impedance cardiogram in a similar fashion. Therefore, a ratio of $D / D+S$, the mitral $\mathrm{RF}_{\mathrm{I}}$ would be expected to be less affected by these external factors.

The characteristic changes observed in the impedance cardiogram of patients with mitral regurgitation do appear related to the lesion. The pronounced diastolic " $O$ " wave in mitral regurgitation coincides with early rapid diastolic filling of the left ventricle. ${ }^{3}$ The mitral $\mathrm{RF}_{\mathrm{I}}$ changes in patients with mitral regurgitation who perform both isometric handgrip and inhaled amyl nitrite are consistent with this hypothesis. Isometric handgrip, by increasing the left ventricular afterload, increases mitral regurgitation. This was reflected by a larger mitral RF r. In contrast, amyl nitrite, a drug which decreases left ventricular afterload, thus decreasing mitral regurgitation, decreased mitral $R F_{I}$. In three patients, who underwent surgical replacement of the mitral valve, the "O" point of the impedance cardiogram, which had been increased, returned to a normal configuration, further suggesting that these impedance cardiogram changes are related to the haemodynamic abnormality.

The areas $\mathrm{S}$ and $\mathrm{D}$ of the impedance cardiogram did not correlate respectively with either the forward or the regurgitant stroke volumes. Though quantitative studies have validated the usefulness of the impedance cardiogram to monitor left ventricular stroke volume in normal subjects, ${ }^{15-17}$ poor correlation of the impedance to cardiac cardiogram output in patients with regurgitant lesions has been described. ${ }^{3}$ During systolic ejection, stroke volume moves both into the aorta from the left ventricle and into the left atrium. These blood volumes moving in two different directions may be cancelling some of the signal responsible for the $\mathrm{dZ} / \mathrm{dt} \max$. Therefore, $\mathrm{dZ} / \mathrm{dt} \max$ is lower in mitral regurgitation and does not correlate with the angiographic stroke volume. The impedance cardiogram signal may be responding, in part, to the changes in blood velocity which may be causing the alterations in the impedance cardiogram wave form independent of the stroke volume. We have shown that in dogs with acute experimental aortic regurgitation, changes in the impedance cardiogram wave form are produced, which are quantitatively related to directional blood flow within the aorta as measured by an electromagnetic flow probe. ${ }^{18}$

The impedance cardiogram is a relatively simple non-invasive technique which allows repeated studies of patients with mitral regurgitation. Changes in the impedance cardiogram correlate with the severity of mitral regurgitation as measured during cardiac catheterisation. Because the factors which affect the impedance cardiogram are not completely understood, the utility of this instrument in measuring the degree of mitral regurgitation between patients and changes of mitral regurgitation over time in individual patients should be cautiously interpreted.

The authors thank Drs Melvin Marcus and Donald Brown for reviewing the manuscript.

\section{References}

1 Kubicek WG, Karnegis JN, Patterson RP, Witsoe DA, Mattson RH. Development and evaluation of an impedance cardiac output system. Aerospace Med 1966; 37: 1208-12.

2 Lababidi Z, Ehmke DA, Durnin RE, Leaverton PE, Lauer RM. Evaluation of impedance cardiac output in children. Pediatrics 1971 ; 47: 870-9.

3 Lababidi Z, Ehmke DA, Durnin RE, Leaverton PE, Laurer RM. The first derivative thoracic impedance cardiogram. Circulation 1970; 41: 651-8.

4 Patel MR, Schieken RM, Jordan HR, Lauer RM, Laughlin DE. Evaluation of the impedance cardiogram in aortic and mitral regurgitation (abstract). In Proceedings of 28th Annual Conference on Engineering in Medicine and Biology. Vol 17. Chevy Chase, Maryland: Alliance for Engineering in Medicine and Biology, 1975: 98.

5 Greene DG, Carlisle R, Grant C, Bunnell IL. Estimation of left ventricular volume by one-plane cineangiography. Circulation 1967; 35: 61-9.

6 Sandler H, Dodge HT. Use of single plane angiocardiograms for the calculation of left ventricular volume in man. Am Heart $\mathcal{F} 1968$; 75: 325-34.

7 Dodge HT, Sandler H, Ballew DW, Lord JD Jr. The use of biplane angiocardiography for the measurement of left ventricular volume in man. Am Heart $\mathcal{f}$ 1970; 60: 762-76.

8 Kennedy JW, Trenholme SE, Kasser IS. Left ventricular volume and mass from single plane cineangiocardiogram. A comparison of anteroposterior and right anterior oblique methods. $\mathrm{Am}$ Heart $\mathcal{F} 1970$; 80: 343-52.

9 Sandler H, Dodge HT, Hay RE, Rackley CE. Quantitation of valvular insufficiency in man by angiocardiography. Am Heart $\mathcal{F}$ 1963; 65: 501-13.

10 Arvidsson H, Karnell J. Quantitative assessment of mitral and aortic insufficiency by angiocardiography. Acta Radiol 1964; 2: 105-19.

11 Kennedy JW, Yarnall SR, Murray JA, Figley MM. Quantitative angiocardiography. IV. Relationships of left atrial and ventricular pressure and volume in mitral valve disease. Circulation 1970; 41: 817-24.

12 Snedecor GW, Cochran WG. Statistical methods. 6th ed. Ames, Iowa: Iowa State University Press, 1969.

13 Kubicek WG, Kottke FJ, Ramos MU, et al. The Minnesota impedance cardiograph: theory and applications. Biomed Eng 1974; 9: 410-16.

14 Schieken RM, Patel MR, Falsetti HL, Barnes RW, Lauer RM. Effect of aortic valvular regurgitation upon the impedance cardiogram. $B r$ Heart $\mathcal{f} 1978$; 40: 958-63. 
15 Denniston JC, Maher JT, Reeves JT, et al. Measurement of cardiac output by electrical impedance at rest and during exercise. F Appl Physiol 1976; 40: 91-5.

16 Lenz RJ, Thomas TA, Wilkins DG. Cardiovascular changes during laparoscopy. Studies of stroke volume and cardiac output using impedance cardiography. Anaesthesia 1976; 31: 4-12.

17 Nagger CZ, Dobnik DB, Flessa AP, Kripke BJ, Ryan TJ. Accuracy of the stroke index as determined by the transthoracic electrical impedance method. Anaesthesiology 1975; 42: 201-5.
18 Schieken RM, Patel MR, Jordan HR, et al. Quantitative assessment of aortic regurgitation using thoracic impedance cardiogram. Cathet Cardiovasc Diagn $1980 ; 6$ : 61-71.

Requests for reprints to Dr Richard M Schieken, Division of Pediatric Cardiology, Universicy of Iowa Hospitals and Clinics, Iowa City, Iowa 52242, USA. 